\title{
E-GUIA: SISTEMA PARA PROVER MOBILIDADE E ACESSIBILIDADE AOS DEFICIENTES VISUAIS NOS SERVIÇOS DE TRANSPORTES URBANOS
}

\author{
Philippi Sedir Grilo de Morais \\ Instituto Federal de Educação, Ciência e Tecnologia do Rio Grande do Norte, Diretoria \\ Acadêmica de Gestão e Informática. philippi.sedir@gmail.com \\ Daniele Montenegro da Silva Barros \\ Instituto Federal de Educação, Ciência e Tecnologia do Rio Grande do Norte, Diretoria \\ Acadêmica de Gestão e Informática. monte.daniele@gmail.com \\ Ricardo Alexsandro de Medeiros Valentim \\ Professor da Universidade Federal do Rio Grande do Norte, Centro de Tecnologia, \\ Departamento de Engenharia de Biomédica. ricardo.valentim@ufrnet.br
}

\section{Robinson Luís de Souza Alves}

Professor do Instituto Federal de Educação, Ciência e Tecnologia do Rio Grande do Norte, Campus Natal Central, Diretoria Acadêmica de Gestão e Informática. robinson.alves@ifrn.edu.br

João Marcos Teixeira Lacerda

Professor do Instituto Federal de Educação, Ciência e Tecnologia do Rio Grande do Norte, Campus Currais Novos. joao.lacerda@ifrn.edu.br

João Paulo Queiroz dos Santos

Professor do Instituto Federal de Educação, Ciência e Tecnologia do Rio Grande do Norte, Campus Zona Norte. joao.queiroz@ifrn.edu.br

\section{Sidney Soares Trindade}

Instituto Federal de Educação, Ciência e Tecnologia do Rio Grande do Norte, Diretoria

Acadêmica de Gestão e Informática. sidney@info.ufrn.br

\section{Jailton Carlos de Paiva}

Universidade Federal do Rio Grande do Norte, Centro de Tecnologia, Departamento de

Engenharia da Computação e Automação. jailtoncarlos@gmail.com

\section{Custódio Leopoldino Brito Guerra Neto}

Professor da Universidade Federal do Rio Grande do Norte, Centro de Tecnologia,

Departamento de Engenharia de Biomédica. custodioguerra@yahoo.com.br

Danilo Alves Pinto Nagem

Professor da Universidade Federal do Rio Grande do Norte, Centro de Tecnologia,

Departamento de Engenharia de Biomédica.nagem@ufrnet.br

\section{RESUMO}

A mobilidade corresponde à facilidade de deslocamento das pessoas na cidade em função das complexas atividades nela desenvolvidas, constituindo como um bem importante para a qualidade de vida dos seus habitantes. Para o deficiente visual ter mobilidade significa melhorar a qualidade de vida, principalmente se esse deficiente necessita usar o sistema de transporte de serviço urbano. Sendo assim, o presente artigo tem por objetivo apresentar um sistema que visa o aspecto de inclusão de pessoas com deficiência visual através da união de tecnologia e acessibilidade. O e-Guia é um sistema que trás informações aos deficientes visuais que utilizam transportes urbanos, especificamente ônibus, através da utilização dos dispositivos móveis. Para a realização desse projeto foi necessário projetar uma arquitetura que possibilitasse a comunicação entre o usuário, o ônibus e o servidor, 
que é responsável pelo recebimento das informações, e como também, por avisar ao usuário que o ônibus desejado está próximo de sua parada. Foram realizados experimentos chamados de testes de campo, que foram executados em um ambiente real. Ao final desses experimentos a arquitetura foi validada, e como resultados mostraram o bom desempenho do sistema, demonstrando que o usuário foi capaz de saber com antecedência de 15 a 30 segundos à chegada do ônibus mais próximo à parada.

PALAVRAS-CHAVE: mobilidade, deficiência visual, dispositivos móveis, serviço de transporte urbano.

\title{
E-GUIA: SYSTEM FOR PROVIDING MOBILITY AND ACCESSIBILITY TO VISUALLY IMPAIRED IN URBAN TRANSPORT SERVICES
}

\begin{abstract}
The ease of mobility corresponds to the displacement of people in the city due to the complex activities developed there, as constituting an important asset to the quality of life of its inhabitants. For the visually impaired have mobility means improving the quality of life, especially if the poor need to use the transportation system of urban service. Thus, this final paper aims to present a system that looks inclusion of visually impaired people through the union of technology and accessibility. e-Guia is a system that brings information to the visually impaired using urban transport, particularly buses, through the use of mobile devices. For the realization of this project it was necessary to design an architecture that would enable the communication between the user, the bus, and the remote server, which the last one is responsible for receiving the information, and also, by prompting the visually impaired that the desired bus is close to the bus stop. Experiments called field tests were performed in a production environment. At the end of these experiments the architecture was validated, and results showed good performance of the system, indicating that the user was able to know in advance 15-30 seconds at arrival to the nearest bus stop.
\end{abstract}

KEYWORDS: mobility, visual impairment, mobile devices, urban transportation service.

\section{E-GUIA: SISTEMA PARA PROVER MOBILIDADE E ACESSIBILIDADE AOS DEFICIENTES VISUAIS NOS SERVIÇOS DE TRANSPORTES URBANOS}

\section{INTRODUÇÃO}

As novas formas de comunicação sem fio proporcionaram profundas transformações na forma de como a cidade é apropriada. Hoje as novas mídias tais como palms, smartphones ou tablets dinamizaram os processos de emissão e recepção da informação.

Essa tecnologia aliada às novas formas de mídias comunicacionais reconfiguraram os espaços urbanos e dinamizam o transporte público transformando as cidades em um lugar de mobilidade (LEMOS, 2007). Esse fato ganha uma relevância extrema quando se trata de pessoas com alguma deficiência como a visual. 
Estima-se que no Brasil, segundo a Associação Brasileira de Assistência ao Deficiente Visual - LARAMA, quase $3,5 \%$ da população possui dificuldade ou nenhuma capacidade de enxergar e foram classificados como deficiência visual severa.

Dentro desse contexto, cada dia mais as tecnologias assistivas, que segundo Bersch (2008) são os recursos e serviços que contribuem para proporcionar ou ampliar habilidades funcionais de pessoas com deficiência, tem promovido a independência e inclusão dessas pessoas.

Diversos trabalhos foram encontrados na literatura relacionados ao tema proposto neste artigo. Siqueira (2012) faz um estudo entre sistemas de rastreamento veicular aplicado ao transporte urbano para propor um modelo de dados para armazenamento de informações de veículos de transporte urbano em tempo real. $\mathrm{O}$ modelo de dados proposto consiste em diagramas de entidade e relacionamento e de domínio, incluindo também diagramas da UML (Universal Modeling Language) utilizados para a validação do trabalho. Também apresenta tecnologias móveis utilizadas, que servem de base para criação de uma infraestrutura de monitoramento de veículos e itinerários, permitindo a geração de informações pertinentes ao usuário do sistema de transporte urbano.

Takagi et al. (2010) propõe um Sistema de Monitoramento e Predição de Tempo de Chegada de Ônibus. Esse sistema, através de um aplicativo web, informa à previsão do tempo restante para um ônibus chegar a um determinado ponto, exibindo a sua posição em tempo real. É utilizado um módulo embarcado no ônibus a ser monitorado, equipado com um receptor de sinal GPS e um modem GPRS, que envia periodicamente para um servidor dados acerca de sua posição e velocidade. A previsão será realizada utilizando-se algoritmos que levarão em conta informações históricas do trecho percorrido pelo ônibus, armazenadas em uma base de dados.

Um importante trabalho correlato pode ser encontrado em Bastos \& Jaques (2010), que desenvolveram um Sistema Web denominado Antares. Esse sistema possibilita ao usuário à consulta de rotas do transporte de serviço urbano, cuja determinação da melhor rota para o usuário utiliza algoritmos de Inteligência Artificial e a API (Application Programming Interface) do Google Maps para visualização em forma de mapas.

Nesse contexto verifica-se que vários trabalhos foram realizados com o objetivo de aliar tecnologia a utilização de transporte coletivo urbano. $\mathrm{O}$ trabalho apresentado nesse artigo visa o aspecto de inclusão a pessoas com deficiência visual através da união de tecnologia e acessibilidade. $\mathrm{O}$ e-Guia é um sistema que trás informações aos deficientes visuais que utilizam transportes urbanos, especificamente ônibus, através de dispositivos móveis. $\mathrm{O}$ sistema é dividido em três módulos: Ônibus e parada, servidor e usuário. O Módulo Ônibus e Parada é um conjunto de hardware com software embarcado que fica localizado no interior do ônibus e que transmite constantemente informações de geolocalização (latitude e longitude) para o Módulo Servidor. O Módulo Servidor concentra e processa informações sobre a localização dos ônibus, enviadas pelo Módulo Ônibus dentro de cada veículo de transporte, também disponibiliza um serviço para consultas para clientes. $\mathrm{O}$ Módulo Usuário permite que usuários com ou sem deficiência visual, por meio de tecnologias móveis assistivas, faça consultas de linhas de ônibus e obtenha estimativas de tempo e distância. 


\section{TECNOLOGIAS UTILIZADAS PARA A CONSTRUÇÃO DO SISTEMA}

Para o desenvolvimento do sistema exposto neste artigo, foram utilizadas as seguintes tecnologias: a Linguagem de Programação Java, um framework de desenvolvimento web, o banco de dados PostgreSQL, a plataforma de dispositivos móveis Android, o Padrão REST, o protocolo de comunicação GPRS (General Packet Radio Service).

A linguagem de programação Java, criada pela Sun Microsystems, possui recursos de suporte a API para desenvolvimento de sistemas distribuídos através da Internet (CHRISTOPHER, 2000). Ela foi utilizada por dispor de um conjunto de ferramentas que permite o desenvolvimento de aplicações de grande porte, como o framework Play (ELLIS, 2011) para criação de sistemas, ao qual serviu como base para à construção do servidor núcleo do e-Guia que armazena e processa dados sobre ônibus e linhas.

Os dados utilizados são armazenados em um banco de dados PostgreSQL, que um Sistema de Gerenciamento de Banco de Dados Relacional (SGBDR) escolhido por oferecer integridade de dados transacional, alta disponibilidade e suporte a integração com linguagens de programação como o Java.

A Plataforma Android foi escolhida para o desenvolvimento do aplicativo móvel por ser uma plataforma completa, que inclui Sistema Operacional (S.O.), middleware e aplicações, possuindo também, diversos componentes com uma variada disponibilidade de bibliotecas e interface gráfica e ao qual facilita o desenvolvimento de aplicativos, utilizando a linguagem Java (LECHETA, 2009). Adicionalmente, a plataforma possui suporte a interfaces faladas e de síntese de voz, permitindo desenvolver aplicações com suporte à acessibilidade a deficientes visuais.

O estilo arquitetural REST é um conjunto de especificações utilizado sobre o protocolo HTTP (Hypertext Transfer Protocol) que define um padrão para a comunicação de webservices, visando escalabilidade e flexibilidade no formato das mensagens (MORO et al. 2009). É utilizado na implementação do web service que permite interação do servidor núcleo do e-Guia com outras partes do sistema.

As redes de telefonia móvel estão presentes no cotidiano, criando uma atmosfera que permite a comunicação sem barreiras entre dispositivos sem fio dentro do espaço geográfico que antes apenas suportava voz, foram estendidos para acesso aos dados na internet (KUROSE; ROSS, 2006). A evolução dessas redes expandiu a capacidade para transferências de dados a velocidades satisfatórias com o surgimento das tecnologias GPRS e 3G (Terceira geração de redes móveis). É possível manter comunicações TCP (Transmission Control Protocol) de forma ininterrupta, que possibilita prover serviços móveis com um desempenho satisfatório. Neste trabalho, o papel das redes móveis é possibilitar a comunicação via sockets TCP entre os dispositivos móveis e o servidor.

\section{VISÃO ARQUITETURAL DO E-GUIA}

A arquitetura de software pode ser conceituada como à organização de um sistema incorporada em seus componentes e em seus relacionamentos com o ambiente (IEEE/1471-2000). Sendo a forma de como o sistema vai interagir com os seus elementos internos e com os elementos externos a ele. 
A arquitetura proposta foi desenvolvida de forma modularizada e distribuída onde cada fluxo de execução descreve uma parte importante do sistema. As partes são distribuídas em máquinas diferentes, sendo executadas sobre diferentes plataformas e comunicando-se mediante a utilização de componentes responsáveis por gerenciar as chamadas remotas, o que possibilita uma maior eficiência, transparência, escalabilidade e suporte a recursos compartilhados.

A Figura 1 representa de forma geral a arquitetura em referência, onde os seus três módulos podem ser divididos em: Módulo Servidor, Módulo Ônibus e da Parada, e Módulo Usuário.

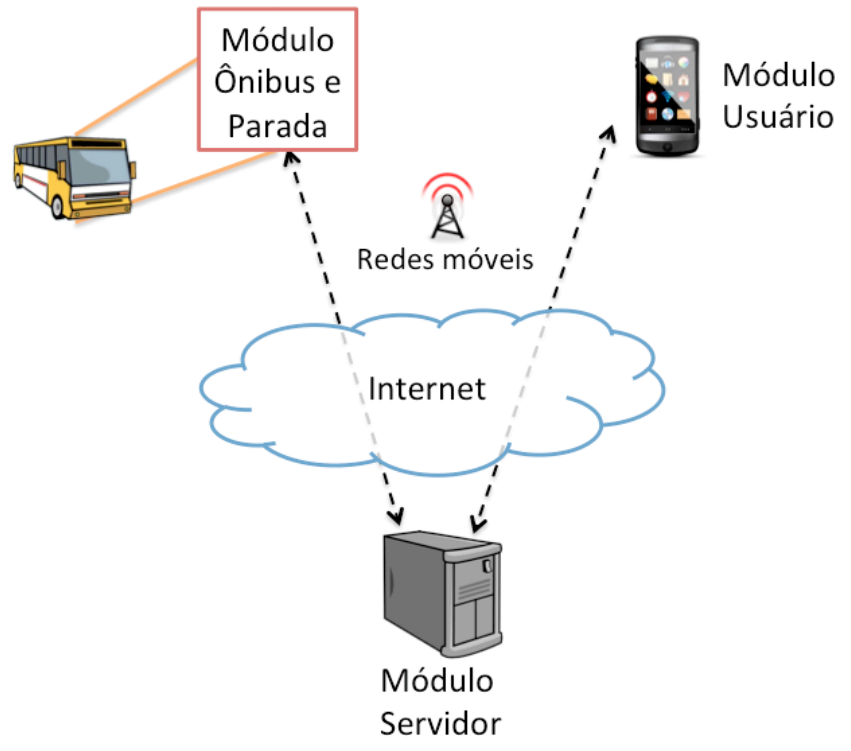

Figura 1 - Visão Geral da Arquitetura.

O Modulo Ônibus e da Parada é um software embarcado, funcionando em conjunto com um hardware chamado de e-Guia Box, que é um equipamento dotado de processador ARM, memória interna, tela LCD touchscreen, GPS e modem GPRS/3G. Esse equipamento foi desenvolvido especialmente para atender as necessidades do sistema, que objetiva a obtenção de dados de geolocalização (latitude e longitude).

O Modulo Ônibus e Parada funciona da seguinte maneira: o e-Guia Box envia ao servidor as informações sobre a localização do ônibus; logo após receber essa requisição, o servidor responde informando quantos deficientes estão esperando na próxima parada, essa integração pode ser visualizada através da Figura 2.

O Modulo Servidor foi criado através do Play, um framework ágil que utiliza a linguagem Java para desenvolvimento de aplicações para a web. Esse módulo é considerado a central de processamento do sistema, um intermediário que interage tanto com o Módulo Usuário e com o Módulo Ônibus e Parada. É responsável pelo gerenciamento do cadastro das linhas, ônibus e paradas, e também pelo recebimento das coordenadas de geolocalização enviadas pelos ônibus através do Módulo Ônibus e Parada. Uma vez que o servidor conhece o estado e localização de todos os ônibus, são realizados cálculos de correção para determinar em qual posição está na rota da linha. Isso possibilita saber, por exemplo, qual ônibus está mais próximo de uma determinada parada. 


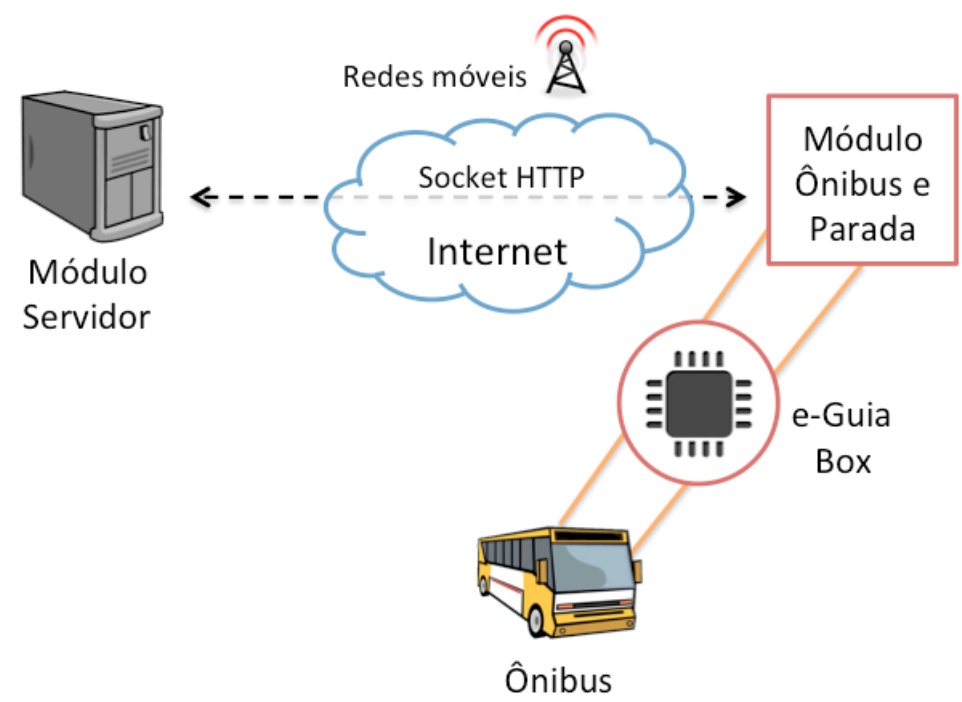

Figura 2 - Interação do Módulo Ônibus e Parada com o Módulo Servidor

A arquitetura utiliza um modelo de dados que possibilita o armazenamento das informações:

- Ponto: utilizado para ganhar as informações sobre a distância do ponto anterior até o ponto atual, e a sequencia que é passado entre os pontos. Esses dados são responsáveis por determinar a posição do ônibus e a rota da linha;

- Posição: armazena os dados sobre a latitude e longitude que representa as coordenadas geográficas de um Ponto;

- Posição_Ônibus: determina a posição atual do Ônibus;

- Parada: armazenam o código e a descrição da parada.

Para possibilitar que os usuários, principalmente deficientes visuais, utilizem o sistema de forma prática e móvel, foi desenvolvido um aplicativo na plataforma de dispositivos móveis Android, chamado de Módulo Usuário. Através dele é permitido ao usuário consultar a distância e tempo médio de chegada do ônibus mais próximo a uma determinada parada.

A interface visual do aplicativo, mostrada na Figura 3, exibe campos necessários para efetuar a consulta: uma lista para seleção da linha e outra para seleção da parada. A acessibilidade para aplicação está integrada na plataforma Android, que provê suporte a leitores de tela para os usuários com baixa ou nenhuma visão. O Usuário, através do Módulo Usuário, escolhe uma linha de ônibus e uma parada e inicia o processo de solicitação. Servidor recebe a solicitação do usuário e responde, enviando constantemente à distância e média de tempo de chegada do ônibus mais próximo. Logo que o ônibus se aproxima da parada a uma distância aproximada a 100 metros, o usuário recebe um aviso final, alertando-o da presença do ônibus. Na Figura 3, é possível visualizar a comunicação entre os Módulos Usuário e Servidor. 


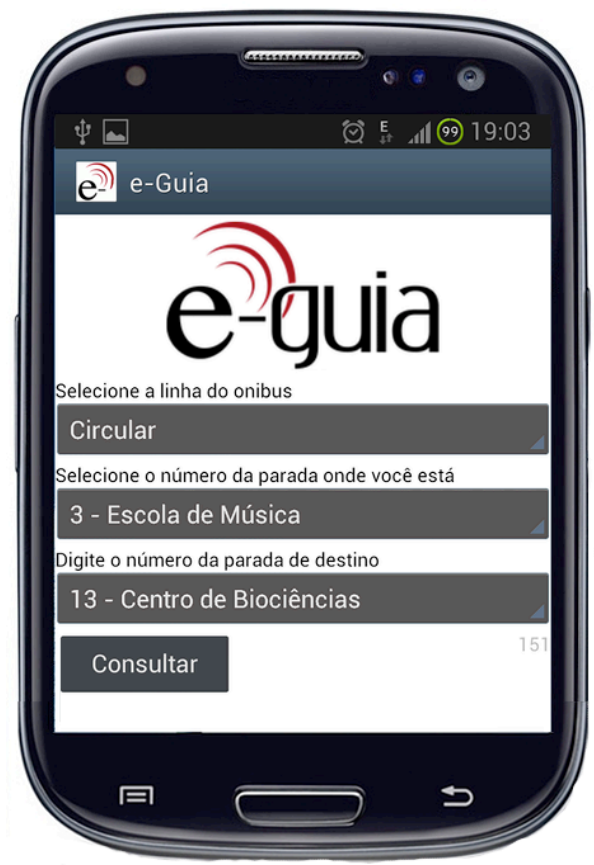

Figura 3 - Aplicativo Móvel

O estilo arquitetural adotado é o Cliente-Servidor que é um modelo de arquitetura que se baseia em um método de distribuição de aplicações computacionais através de multiplataformas, onde as aplicações são divididas entre o servidor de acesso e uma central de dados, que podem comunica-se com vários clientes, com todo o processamento realizado de forma distribuída (DESCHAMPS, et al. 1998). Esse processamento distribuído, também denominado de processamento concorrente utiliza-se do mecanismo de passagem de mensagens para a comunicação entre processos, ao qual possibilita a integração entre os módulos.

Essa distribuição pode ser verificada na Figura 4, que representa a integração entre o Módulo Usuário e o Módulo Servidor. Nessa parte a comunicação entre os módulos acontece da seguinte forma: $\mathrm{O}$ usuário escolhe uma linha de ônibus e uma parada e inicia o processo de solicitação; o servidor recebe essa solicitação e responde com a distância e média de tempo da chegada do ônibus mais próximo, utilizando-se de uma velocidade média estimada; logo após, a resposta é enviada ao usuário, que recebe constantemente mensagens sobre o estado da localização do ônibus até a aproximação dele na parada.

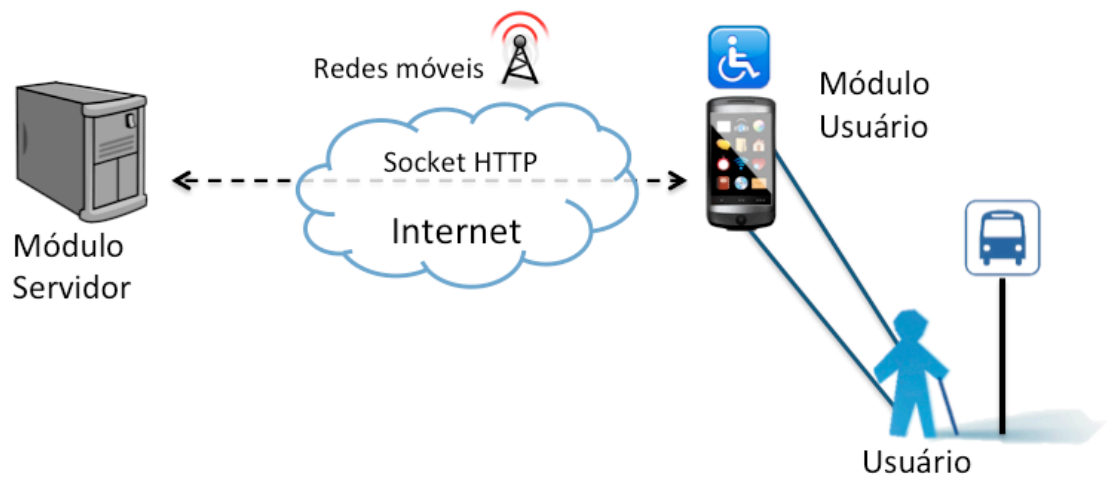

Figura 4 - Interação do Módulo Usuário com o Módulo Servidor 


\section{EXPERIMENTOS}

A fim de validar a arquitetura, foram realizados experimentos no sistema e-Guia chamados de testes de campo, executados em um ambiente real. Para realizar tais testes, e também validar a interface dos usuários, contou-se com a participação de um deficiente visual. Os testes incluíram também, dois ônibus reais equipados cada um com um e-Guia Box, ao qual continha o Módulo Ônibus e Parada, um computador de alto desempenho funcionando com o Módulo Servidor.

Os parâmetros para execução dos testes exigiram a utilização de uma linha ônibus em circulação. Para tanto, a linha escolhida foi uma que transporta estudantes aos arredores de uma universidade federal. Também foi necessário acesso a redes móveis $3 \mathrm{G}$ de uma determinada operadora de dados, de forma que os módulos Usuário e Ônibus e Parada pudessem se comunicar através da Internet. Por fim, o deficiente visual foi posicionado em paradas de ônibus aleatórias ao longo do percurso da linha. Além disso, a comunicação foi monitorada a fim de verificar a integridade da mesma.

Com base nos parâmetros estabelecidos, foram realizadas duas abordagens para execução dos testes: Aceitação da usabilidade e Tempo de resposta. Em ambas as abordagens foram preparadas perguntas com respostas predeterminadas para definir níveis de aceitação: Bom, regular e ruim. A aceitação da usabilidade foi elaborada para avaliar o nível de facilidade de utilização do sistema no Módulo Usuário, cujo foco é a utilização por deficientes visuais. E a aceitação de tempo de resposta avalia a eficiência em que as informações chegam ao usuário baseado em uma janela de tempo para que o usuário possa se preparar para a chegada do ônibus.

No fluxo de realização dos testes, o usuário fez uma solicitação através do dispositivo móvel para obter os alertas de tempo e distância do ônibus mais próximo a ele, até que o sistema exibisse um alerta final, indicando a alta proximidade do ônibus em relação à parada. Após cada teste, o usuário deficiente visual avaliou o tempo de resposta, assim como ao final do experimento também avaliou a usabilidade, de acordo com a Tabela 1.

\begin{tabular}{|l|l|l|}
\hline & Tempo de resposta & Usabilidade \\
\hline Bom & $\begin{array}{l}\text { O sistema alertou o usuário } \\
\text { no tempo de 15 a 30 } \\
\text { segundos antes de o onibus } \\
\text { chegar à parada. }\end{array}$ & $\begin{array}{l}\text { utilizar o sistema de } \\
\text { forma satisfatória, sem } \\
\text { qualquer dificuldade. }\end{array}$ \\
\hline Regular & $\begin{array}{l}\text { O sistema alertou o usuário } \\
\text { no tempo de até 15 } \\
\text { segundos antes ou na hora } \\
\text { de o ônibus chegar à parada. }\end{array}$ & $\begin{array}{l}\text { utilizar o sistema, porém } \\
\text { com alguma dificuldade. }\end{array}$ \\
\hline Ruim & $\begin{array}{l}\text { O sistema alertou o usuário } \\
\text { somente após a deixar a a } \\
\text { parada. }\end{array}$ & $\begin{array}{l}\text { O usuário não conseguiu } \\
\text { utilizar o sistema de } \\
\text { forma correta. }\end{array}$ \\
\hline
\end{tabular}

Tabela 1 - Respostas possíveis das avaliações. 


\section{RESULTADOS E DISCUSSÕES}

Os experimentos foram executados de acordo com os parâmetros expostos na seção anterior. Ao todo, foram realizados cinquenta (50) testes ao longo de cinco (5) paradas de ônibus no percurso da linha escolhida. A Tabela 2 demonstra os resultados em relação às duas abordagens.

\begin{tabular}{|l|l|l|}
\hline & Tempo de resposta & Usabilidade \\
\hline Bom & 43 & 1 \\
\hline Regular & 2 & 0 \\
\hline Ruim & 3 & 0 \\
\hline Total & 50 & 1 \\
\hline
\end{tabular}

Tabela 2 - Resultados das avaliações.

De acordo com os resultados apresentados, foi possível notar um bom desempenho do sistema, tanto na usabilidade como no tempo de resposta.

Os testes demonstraram que o usuário foi capaz de saber com antecedência de 15 a 30 segundos à chegada do ônibus mais próximo à parada. Porém houve testes com problemas em relação ao tempo de resposta, pois as requisições de conexão não foram bem sucedidas devido a intermitências na rede de dados móveis.

Partindo para o próximo parâmetro dos experimentos, que foi a avaliação de usabilidade, percebeu-se um alto nível de facilidade de uso do Módulo Usuário.

Um importante aspecto foi notado durante a execução dos testes. Para o funcionamento satisfatório do sistema é necessário o pleno funcionamento das redes de telefonia móvel. Este fato demonstra um possível cenário de falha, que consiste na indisponibilidade dos provedores das redes de dados dentro da área de cobertura ao qual o ônibus está localizado, e como também, o usuário dispor desta tecnologia.

Visto que este trabalho está em fase inicial, há espaço para discussão de trabalhos futuros no sistema e-Guia, que podem incluir a implementação de algoritmos inteligentes que possibilitem estimar melhor o tempo de chegada dos ônibus, levando em consideração o tráfego em situações de congestionamento. Além disso, um aperfeiçoamento com significante impacto e maior autonomia ao deficiente visual seria o acompanhamento do mesmo até o destino, através de mensagens que o informe quando ele estiver próximo ao ponto de descida.

\section{REFERÊNCIAS BIBLIOGRÁFICAS}

1. BASTOS, R; JAQUES, P. A. ANTARES : Um sistema Web de consulta de rotas de ônibus como serviço público. Instituto de Ciências Exatas e Geociências da Universidade Passo Fundo, v. 2, n. 1, p.41-56, 2010. Disponível em: http://www.upf.br/seer/index.php/rbca/article/view/650/519. Acesso em: 16 Dez. 2012.

2. BERSCH, R. Introdução à tecnologia assistiva. CEDI - Centro Especializado em Desenvolvimento Infantil. Porto Alegre, 2008. Disponível em: http://200.145.183.230/TA/4ed/material apoio/modulo2/M2S1A5_Introducao_TA_Rit a_Bersch.pdf. Acesso em: 18 Jan. 2013. 
3. CHRISTOPHER, T. W; THIRUVATHUKAL, G. K. High-Performance Java Platform Computing: Multithreaded and Networked Programming Prentice Hall PTR; 1st edition. 2000

4. DESCHAMPS, E. R. P. Fundamentos da Arquitetura Cliente/servidor. 1998.

5. ELLIS, W. Introducing Play Framework. 2011.

6. KUROSE, J; ROSS, K. Redes de Computadores e Internet. São Paulo: Pearson, 2006.

7. LECHETA, R. Google Android: Aprenda a criar aplicações para dispositivos móveis com o Android SDK. 2 ed. São Paulo, Novatec, 2010.

8. LEMOS, A. Ciberespaço e tecnologias móveis. Processos de territorialização e desterritorialização na cibercultura. Imagem, visibilidade e cultura midiática. Livro da XV COMPÓS. Porto Alegre, 2007. Disponível em: http://www.facom.ufba.br/ciberpesquisa/andrelemos/territorio.pdf. Acesso em: 12 Jan. 2013.

9. MORO, T. D; DORNELES, C.; REBONATTO, M. T. Web Services WS-* versus Web Services REST. Revista de Iniciação Cientifica. v 11, n.1. 2011. Disponível em http://seer.ufrgs.br/reic/article/view/22140. Acesso em: janeiro/ 2013.

10. SIQUEIRA, L. G. Aplicação Bus Tracker: oferecendo uma melhor experiência aos usuários do transporte urbano, a partir da utilização de informações de rastreamento veicular. Universidade Federal do Rio Grande do Sul. Porto Alegre, 2012.

11. TAKAGI, F. T; TEIXEIRA, R. M; MASUKI, T. K. Sistema de Monitoramento e Predição de Tempo de Chegada de Ônibus de Linha. Escola Politécnica da Universidade de São Paulo. São Paulo, 2010. 